\title{
An integrated approach to the use of composite materials for the restoration of reinforced concrete structures
}

\author{
Vladimir Rimshin ${ }^{1}$, and Pavel Truntov ${ }^{1, *}$ \\ ${ }^{1}$ National Research Moscow State University of Civil Engineering, Yaroslavskoe shosse, 26, \\ Moscow, 129337, Russian Federation
}

\begin{abstract}
The article presents the results of a technical inspection of the state of the structures of the object. To conduct the study, horizontal structures of the sludge pool that were exposed to the carbonization reaction were taken for the objects under investigation. Defects and damages of the considered structures revealed during visual inspection are described. The degree of carbonization of reinforced concrete structures was determined by the phenolphthalein sample method. According to the results of the technical inspection, a verification calculation of the beam was carried out in order to determine its bearing capacity for assessing the suitability for further operation after restoration and strengthening. The calculation was performed using software. Based on the calculation results, data on the bearing capacity of the beam reinforced with composite materials were determined. The option of restoring and strengthening the beam using external reinforcement based on carbon fibers FibArm 230/150 is presented. The restoration was carried out taking into account the carbonized concrete layer. Based on the results of the study, an assessment is given of the application of an integrated approach to the restoration and strengthening of structures with composite materials, taking into account the carbonized concrete layer.
\end{abstract}

\section{Introduction}

In modern construction, one of the main reasons of wear of reinforced concrete structures is the reinforcement corrosion. Due to corrosion, the adhesion of reinforcement to concrete is reduced, cracks are formed and the protective layer of concrete is destroyed, as a result of which the bearing capacity of reinforced concrete structures is reduced. One of the main causes of reinforcement corrosion is carbonation. Carbonation is the changes that occur in concrete on Portland cement when exposed to carbon dioxide CO2. Due to the destruction of concrete because of the corrosion of the reinforcement, it is necessary to initially restore the structure of concrete and then to possibly strengthen these structures in the future.

* Corresponding author: pavel truntov@mail.ru 


\section{Materials and Methods}

The object of the survey was built in 1968. The constructions of the sludge pool which were formerly exposed to carbon dioxide (CO2), as a result of which calcite $\mathrm{CaCO} 3$ was formed in the body of the structure (which indicates the process of carbonation in the body of the reinforced concrete structure) were taken to perform the study. During the inspection the following was discovered:

-destruction of the concrete protective layer of beams with exposure and corrosion damage to power reinforcement in the lower zone and supporting nodes;

-violation of the adhesion of the working reinforcement to concrete due to corrosion of the reinforcement and destruction of concrete

- longitudinal cracks in concrete formed as a result of reinforcement corrosion.

As a result of a visual inspection of the structures of object of study, beams were revealed that corroded the reinforcement (Fig. 1).

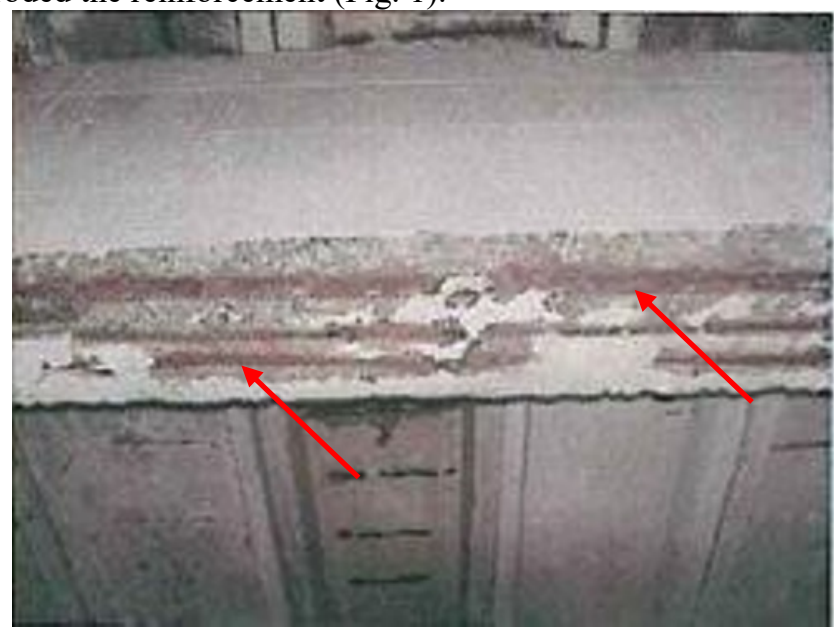

Fig. 1. Corrosion of reinforcement in the beam detected during a technical inspection

During the phenolphthalein test, it was found that the $\mathrm{pH}$ of the medium is less than 8 . The depth is more than the thickness of the concrete protective layer (Fig. 2). A phenolphthalein sample was used with a $1 \%$ solution of phenolphthalein and ethanol.

Fig. 2. The absence of visible signs of concrete carbonation according to the phenolphthalein test 
In the paragraph to follow a calculation was performed in order to verify the structure. A plan for the restoration of the damaged structure was made based on the calculation results.

\section{Calculations and Results}

The article proposes the calculation of strengthening reinforced concrete beams with canvas based on carbon fibers FibArm Tape 230/150. The purpose of this calculation is to determine the load-bearing capacity of the beam to assess its suitability for further operation after restoration work.

The characteristics of the FibArm Tape 230/150 composite material are presented in Table 1.

Table 1. Characteristics of FibArm Tape 230/150

\begin{tabular}{|c|c|c|c|c|}
\hline $\begin{array}{c}\text { Type of } \\
\text { composite } \\
\text { material }\end{array}$ & $\begin{array}{c}\text { Estimated } \\
\text { thickness, } \mathrm{mm}\end{array}$ & $\begin{array}{c}\text { Tensile strength, } \\
\mathrm{MPa}\end{array}$ & $\begin{array}{c}\text { The modulus of } \\
\text { tensile elasticity, } \\
\mathrm{GPa}\end{array}$ & $\begin{array}{c}\text { Monolayer area, } \\
\mathrm{mm}^{2}\end{array}$ \\
\hline $\begin{array}{c}\text { FibArm Tape } \\
230 / 150\end{array}$ & 0,128 & 4000 & 245 & 19,2 \\
\hline
\end{tabular}

The beam is made of B15 class concrete. The maximum dimensions of the beam are $600 \times 200 \mathrm{~mm}$. Figure 3 shows a plot of the bending moments of the beam.

\begin{tabular}{l|l|l|l|}
48.6 & 112.9 & 120.9 & 112.9 \\
\hline $\mathrm{kN*m}$ & & 48.6 \\
\hline
\end{tabular}

Fig. 3. The plot of the bending moments of the beam.

Estimated tensile strength:

$$
R_{f}=\frac{\gamma_{f 1} \gamma_{f 2} R_{f, n}}{\gamma_{f}}=\frac{0,9 \cdot 0,9 \cdot 4000}{1,2}=2700 \mathrm{MPa}
$$

Taking into account the existing steel reinforcement during the calculation of the reinforced structure, the following condition must be met:

$$
R_{f} \leq\left(\varepsilon_{s 2}-\varepsilon_{s}^{0}\right) E_{f}
$$

$R_{f}=2700 \leq 1225$, condition is not met, assuming $R_{f}=1225 \mathrm{MPa}$

$$
\varepsilon_{s}^{0}=\frac{12,09}{0,209 \cdot 71530} \cdot 27=0,02
$$

The calculation of the strength of the cross sections of bent elements reinforced with external reinforcement of composite materials should be carried out from the condition:

$$
\begin{gathered}
M \leq M_{u l t} \\
M_{u l t}=R_{b} \cdot b \cdot x\left(h_{0}-0,5 \cdot x\right)+R_{s c} \cdot A^{\prime}{ }_{s}\left(h_{0}-a^{\prime}\right)+R_{f} \cdot A_{f} \cdot a \\
M=120,9 \mathrm{kN} \cdot \mathrm{m} \leq M_{u l t}=131,1 \mathrm{kN} \cdot \mathrm{m}
\end{gathered}
$$

The condition is met, we take 1 layer of tape along the lower edge of the beam.

A bending element was also calculated from inclined sections on the action of lateral forces (Fig. 4). The calculation was performed based on the condition:

$$
Q \leq Q_{b}+Q_{s w}+Q_{f w}
$$

$Q_{b}$ - lateral force perceived by concrete in an inclined section;

$Q_{s w}$ - lateral force perceived by steel transverse reinforcement installed in an inclined section with step sw; 
$Q_{f w}$ - lateral force perceived by transverse reinforcement made of composite materials in an inclined section, determined by the formula:

$$
Q_{f w}=\psi_{f} \frac{A_{f w} R_{f w} \sin \alpha C_{f w}}{s_{f}}
$$

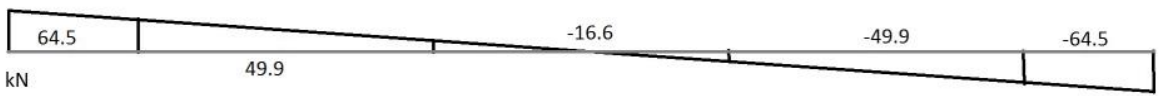

Fig. 4. The plot of the lateral forces

$$
\begin{aligned}
& Q_{h}=87,21 \mathrm{kN} \\
& Q_{s w}=186,5 \mathrm{kN} \\
& Q_{f w}=38,97 \mathrm{kN} \\
& Q=64,5 \leq 87,21+186,35+38,97=312,53 \mathrm{kN}
\end{aligned}
$$

The external transverse reinforcement is not needed according to the calculations, structurally we assume 3 external clamps on three sides of a wide $75 \mathrm{~mm}$ at the beam support, at a distance of $\mathrm{L} / 8$ and $\mathrm{L} / 4$, to a height not bringing $20 \mathrm{~mm}$ to the upper edge of the beam.

Based on the results of the technical examination, it was decided to restore the structure of concrete and reinforcement with further strengthening of the beam with composite materials according to the results of verification calculation.

\section{Discussion}

An example of strengthening the beams was put together based on the results of the technical inspection and verification calculation.

The scheme of restoration and reinforcement of beams is shown in Figures 5 and 6.

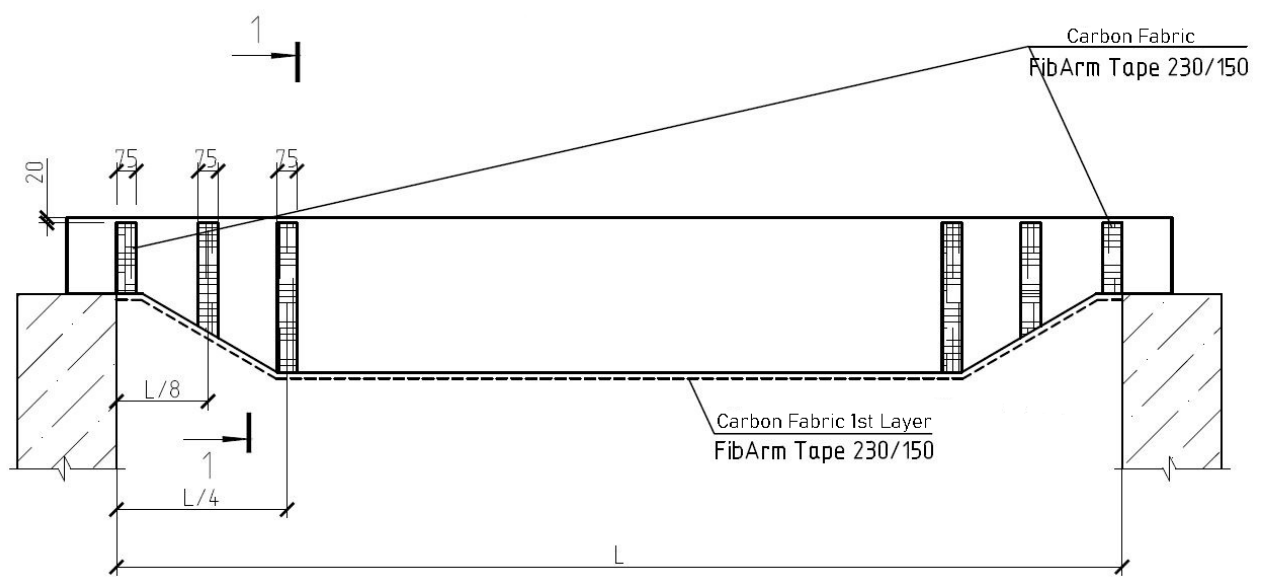

Fig. 5. Beam reinforcement scheme with composite materials 


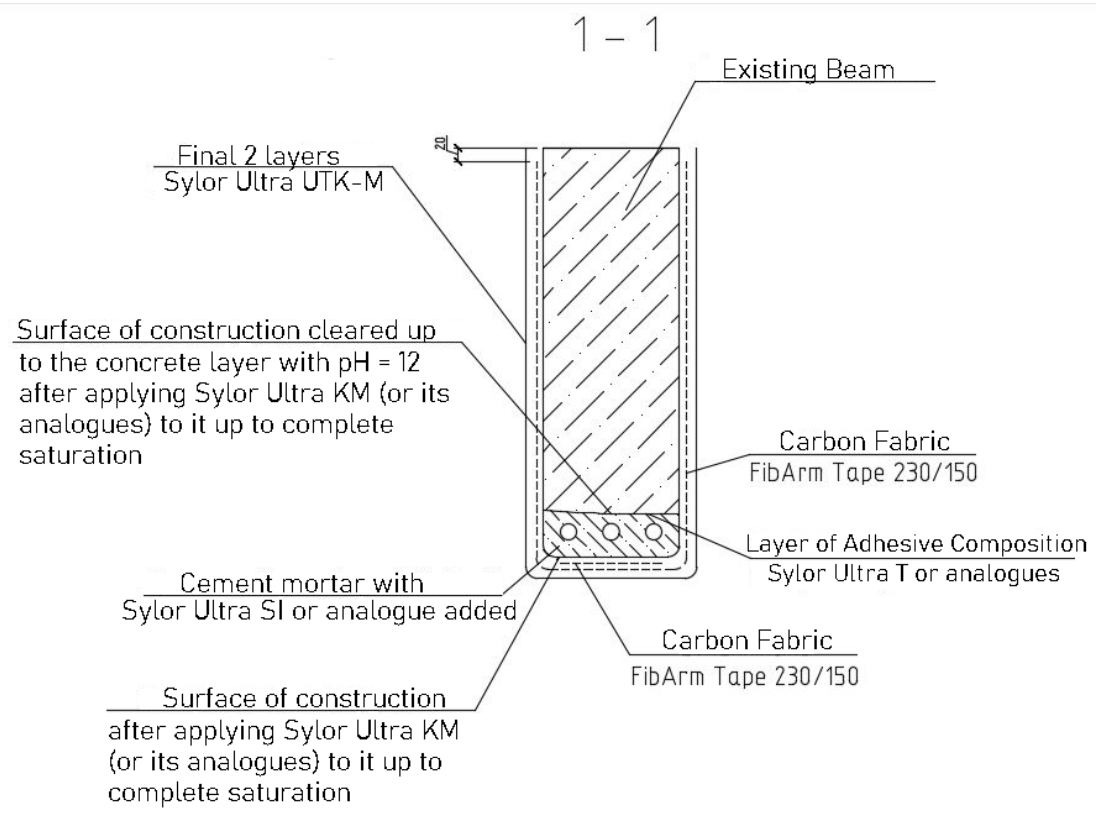

Fig. 6. Section 1-1 of the restored and reinforced beam

\section{Conclusions}

An integrated approach to restoration with further strengthening of composite materials can increase the durability of the structure, as well as provide the required load-bearing capacity of the structure in the further operation of the facility.

If the destruction of the protective layer of concrete and corrosion of the reinforcement is detected, the most probable cause is the carbonation of concrete with increased exposure to $\mathrm{CO} 2$ on the operated structure.

The use of composite materials in the construction and restoration of concrete structures makes it possible to minimize the likelihood of their destruction during operation.

\section{References}

1. A.L. Krishan, V.I. Rimshin, E.A. Troshkina, IOP Conference Series: Materials Science and Engineering 463(2), 022062. (2018).

2. V.I. Rimshin, A.A. Pudova, L.I. Shubin, Izvestiya Vysshikh Uchebnykh Zavedenii, Seriya Teknologiya Tekstil'noi Promyshlennosti, (3), c. 287-293. (2018).

3. S.A. Korotaev, V.I. Kalashnikov et al., Ecology, Environment and Conservation 22 (3), c. 1159-1164. (2016).

4. A. Varlamov, V. Rimshin, S. Tverskoi IOP Conference Series: Materials Science and Engineering, 463 (2), 022028. (2018)

5. E. Kuzina, A. Cherkas, V. Rimshin, IOP Conference Series: Materials Science and Engineering, 365 (3), 032053. (2018)

6. Y. Bazhenov, V. Erofeev et al., Engineering Solid Mechanics, 4 (4), pp. 219-225. (2016) 
7. A. Varlamov, V. Rimshin, S. Tverskoi IOP Conference Series: Materials Science and Engineering, 463 (2), 022029. (2018)

8. A. Varlamov, V. Rimshin, S. Tverskoi Materials Science Forum 931 MSF, c. 340-345. (2018).

9. . Krishan, E. Troshkina, Research Journal of Pharmaceutical, Biological and Chemical Sciences, 7 (3), pp. 2518-2529. (2016)

10. N. Karpenko, V. Eryshev, V. Rimshin, IOP Conference Series: Materials Science and Engineering, 463 (3), 032024. (2018)

11. A. Varlamov, V. Rimshin, S. Tverskoi IFAC-PapersOnLine, 51 (30), pp. 808-811. (2018)

12. V. Erofeev, E. Zavalishin et al., (2016) Research Journal of Pharmaceutical, Biological and Chemical Sciences, 7 (3), pp. 2506-2517. (2016)

13. V. Telichenko, V. Rimshin, E. Kuzina, IOP Conference Series: Materials Science and Engineering, 463(3), 032024. (2018)

14. A. Krishan, M. Narkevich et al., IOP Conference Series: Materials Science and Engineering, 456 (1), 012049. (2018)

15. V. Erofeev, V. Kalashnikov et al., Solid State Phenomena, 871, pp. 28-32. (2016)

16. V. Telichenko, V. Rimshin et al., (2018) MATEC Web of Conferences, 196, 02025. (2018)

17. A. Cherkas, V. Rimshin, MATEC Web of Conferences, 117, 00027. (2017)

18. V. Antoshkin, V. Travush et al., Modern Applied Science, 9 (3), pp. 46-50. (2015)

19. A. Varlamov, V. Rimshin, S. Tverskoi IOP Conference Series: Earth and Environmental Science, 177 (1), 012040. (2018)

20. V. Telichenko, V. Rimshin et al., Journal of Industrial Pollution Control, 33 (1), pp. 1034-1041. (2017)

21. A. Krishan, V. Rimshinet al., Procedia Engineering, 117 (1), pp. 211-217. (2015)

22. V. Rimshin, B. Labudin et al., ARPN Journal of Engineering and Applied Sciences $\mathbf{1 3}$ (11), c. 3851-3856. (2018).

23. A. Krishan, V. Rimshin et al., Izvestiya Vysshikh Uchebnykh Zavedenii, Seriya Teknologiya Tekstil'noi Promyshlennosti, 370 (4), pp. 220-225. (2017)

24. V. Erofeev, A. Bogatov et al., Biosciences Biotechnology Research Asia, 12 (1), pp. 661-669. (2015)

25. E. Kuzina, V. Rimshin, Advances in Intelligent Systems and Computing, 692, pp. 410416. (2018)

26. I. Shubin, Y. Zaitsev et al., Engineering Solid Mechanics, 5 (2), pp. 139-144. (2017)

27. V. Rimshin, E. Larionov et al., Life Science Journal, 11 (11), pp. 278-280. (2014)

28. V. Rimshin, A. Varlamov, Izvestiya Vysshikh Uchebnykh Zavedenii, Seriya Teknologiya Tekstil'noi Promyshlennosti, 3, pp. 63-68. (2018)

29. A. Krishan, V. Rimshin et al., Izvestiya Vysshikh Uchebnykh Zavedenii, Seriya Teknologiya Tekstil'noi Promyshlennosti, (2), pp. 227-232. (2017)

30. V. Bondarenko, A. Kurzanov, V. Rimshin, Vestnik Rossijkoj Akademii Nauk, 70 (11), pp. 1005-1009. (2000) 